\title{
Increasing of Power Output of Racing Motorcycle Engine using of Exhaust System Optimisation
}

\author{
Peter Bigoš (SK) peter.bigos@tuke.sk \\ Michal Puškár(SK) michal.puskar@tuke.sk
}

\section{BIOGRAPHICAL NOTES}

Peter Bigoš, prof. Ing. CSc. Is a university professor nominated in the branch of science "Transport and Handling Engineering". He is a head of the Department of Machine Design, Transport and Logistics at the Faculty of Mechanical Engineering, Technical University of Košice. He graduated at the Faculty of Mechanical Engineering of the former Technical College in Košice (1973). Dissertation thesis he defended in 1980 and in 1983 he was designated as a docent (associate professor). In 1991 he defended his inaugural dissertation at the Technical University of Košice. In the framework of his study stages he visited TU Miskolc, VH Dresden (1981), Polytechnika Rzeszowska (1983), Ruhr Universität Bochum (1989), Imperial College London (1993), TU Budapest (1997). He is a vice-chairman of the "Common professional commission for PhD.-study" in the branch of study "Transport Machines and Machinery" and he is a member of professional commission in the branch "Forensic Engineering", too. He is also member of several advisory boards of domestic and foreign professional journals, as well as he is a guarantor of international and domestic conferences about transport machines and logistics.

Michal Puškár, Ing. PhD. Is a researcher at the Department of Machine Design, Transport and Logistics at the Faculty of Mechanical Engineering, Technical University of Košice. He graduated at the mentioned Department in 2005 and the PhD.-degree received in 2008 with theme of his dissertation thesis: Rising of Power Parameters of Single-Track Transport Means. His current fields of research interest are single-track transport means, piston combustion engines and increasing of their power output and reliability.

\section{KEY WORDS}

Temperature of Exhaust System, Engine Output Performance

\section{ABSTRACT}

An exhaust gas system of a two-stroke piston combustion engine has a significant impact on its maximal power output and speed characteristics. In the first part of this paper there is described an impact of the exhaust gas pipeline system on the output speed characteristics. In the second part is analysed a relation between temperature of exhaust gases and speed characteristics, as well as there is determined an optimal temperature for achievement of the best output characteristics. Results presented in this paper enable to optimise curve of the speed characteristics for application in various kinds of single-track vehicles. 


\section{INTRODUCTION AND AIMS}

An exhaust system is the important supplement of the all engines. It has got the determining influence on engine outgoing parameters for the engines with two-stroke operating cycle. Gas flow in an exhaust system is controlled by means of the difficult principles of non-stationary convection with very difficult calculation. Although the existing special software reached the certain voluminous results, the main merits of work are still in the verification of calculated values on a testing engine. In practice, in most motorcycle firms which are the leaders for development, there are designed several modifications of exhaust systems according to generally known rules. These modified systems are tested and consequently improved with output brake engine tests. One exhaust system is suitable theoretically only for one value of engine speed. It is rather small speed range in practice. The final modification of exhaust system is accommodated to the most using speed values considering the operation possibility in its other modes.

In a cylinder on a piston top edge there is an impulse created by means of the opening of exhaust port. It causes an overpressure wave which is spreading into an exhaust manifold in existing environment with sound speed. In an exhaust manifold there is the sound speed much higher than in the open air. Exhaust manifold gases are step by step exposed the pressure wave influence. In consequence of this fact the gases begin to move outwards from an engine. But there is a reflection back of pressure wave from the opposite cone (Fig.1) what causes the gas oscillation following a longitudinal axle of an exhaust stroke. The aim of the correct dimensioned exhaust system is to improve exhaust of gases from a cylinder and this way to improve the scavenging process. During scavenging of working space with overflowing streams there is the certain mixing of combustion products and fresh fuel-air mixture. The part of fresh fuel-air mixture leaks out into an exhaust port. A fuel-air mixture and combustion products mixing continues there. Close by an engine the gas mixture contains rather few combustion products [3]. That is why there is the effort dimensionally to dispose the exhaust system so that the back movement occurs in the final phase. This back movement comes into existence by reason of the oscillation and again there is the return of off-take gases into the cylinder working space [2].

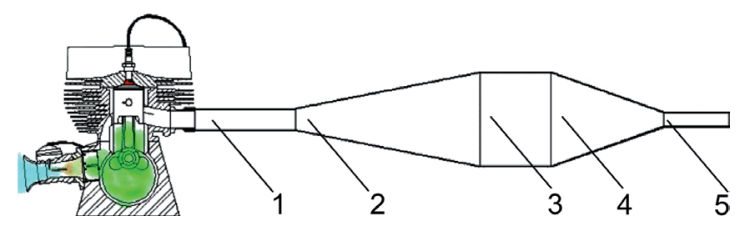

Fig. 1 Parts of Exhaust System: 1-exhaust pipe, 2-expansion cone, 3-rezonator, 4-opposite cone, 5- fishtail

The fuel-air mixture, which contains lower percentage of combustion products, can be used at combustion. In the Fig. 1 there is the design of exhaust system with two-stroke engine in the section [4]. The aim of this article was established in consequence of the described theoretical knowledge about combustion products oscillation in an exhaust system:

"to increase the output of two-stroke combustion engine by means of exhaust system optimization with keeping its main technical parameters (a diameter of diffuser in carburator, a shape of ignition curve, an origin mould of engine bloc and a compression ratio)" The following steps are connected to this main aim: analysis of exhaust system length influence on a maximum engine output and a range of exploitable engine speed,

analysis of combustion product temperature influence in an exhaust system on a maximum engine output and its position in engine speed range.

\section{Experimental Models and Devices}

That is very difficult to develop theoretically the individual components and then to demonstrate the components influence on the output parameters and torque of two-stroke petrol engine. Although there is software for modelling of processes which are operating inside a cylinder and an exhaust system during the combustion, the real results are performed seriously. That is why the experiment was used to achieve the main aim.

It is necessary to choose the experimental model for experimental measurements. The development was realised with this experimental model. Further it is a need to develop the measurement devices (to provide feed back, to give information about a real output proposition for concrete change in an exhaust system).

\subsection{Experimental Models}

The motorcycle Aprilia RS 125 was used as the first experimental model. This single-track vehicle is equipped with the two-stroke engine ROTAX 122 
(Fig.2). In Tab.1 there are the technical parameters of serial version for this engine (specified by producer). Output parameters of our engine ROTAX 122 are higher because we used some racing parts (cylinder, head of cylinder and other parts). But these parts doesn't have an influence on results of this experiment.

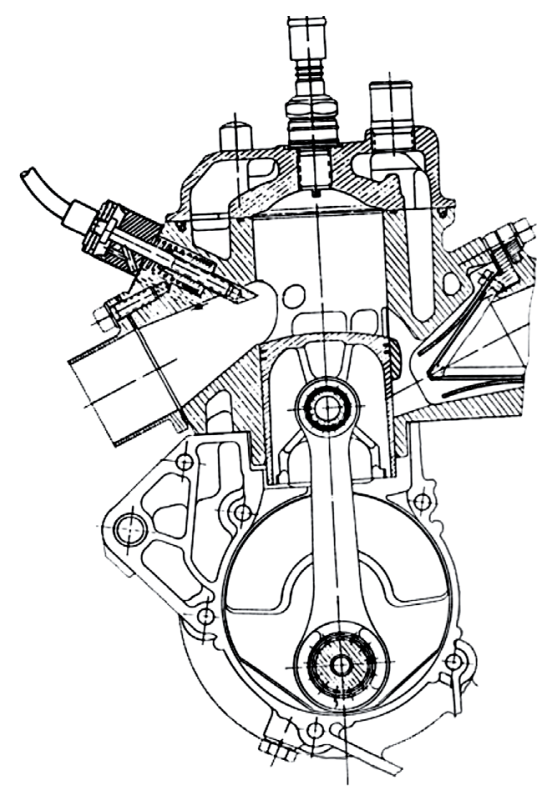

Fig. 2 Engine ROTAX 122

\begin{tabular}{|l|l|}
\hline Type & $\begin{array}{l}\text { a single-cylinder, a two-stroke } \\
\text { engine, liquid cooled, membrane } \\
\text { filled, an electrical-controlled } \\
\text { exhaust power valve }\end{array}$ \\
\hline Capacity & $124,8 \mathrm{~cm}^{3}$ \\
\hline $\begin{array}{l}\text { Bore x Stroke } \\
\text { Compression ration }\end{array}$ & $54 \times 54,5 \mathrm{~mm}$ \\
\hline $\begin{array}{l}\text { Max. output } \\
\text { Max. torque }\end{array}$ & $21,8 \mathrm{~kW}(29,3 \mathrm{HP})-11000 \mathrm{rpm}$ \\
\hline Carburator & $19,1 \mathrm{Nm}(1,95 \mathrm{kpm})-10000 \mathrm{rpm}$ \\
\hline
\end{tabular}

Tab. 1 Technical Parameters of Engine ROTAX

The motorcycle Honda RS 125R was used as the second experimental model. The second singletrack vehicle is equipped with the engine Honda 125. The principle of filling and scavenging of this engine is similar as that is for the engine ROTAX 122. The technical parameters of serial version of this motorcycle are also similar. Only the diameter of carburator diffuser $(39 \mathrm{~mm}$ ) in the shape of an ignition curve is different and that is why a maxi- mum output is higher.

\subsection{Experimental Devices}

Two testing and measuring devices were developed for a need of experimental measurements.

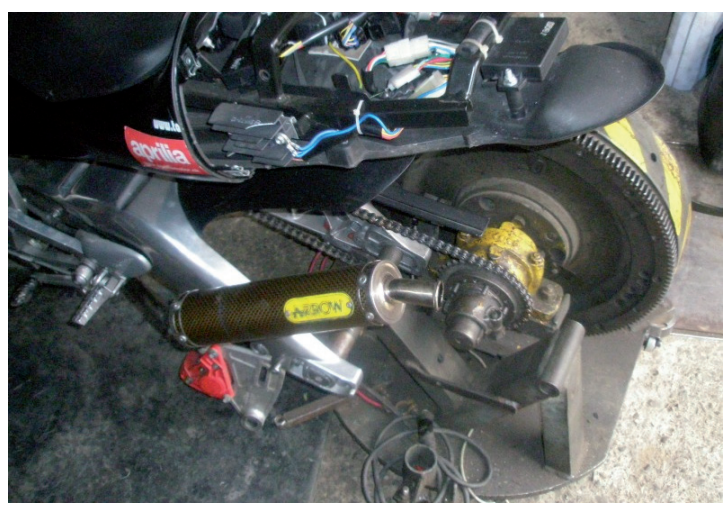

Fig. 3 Output (Engine) Brake

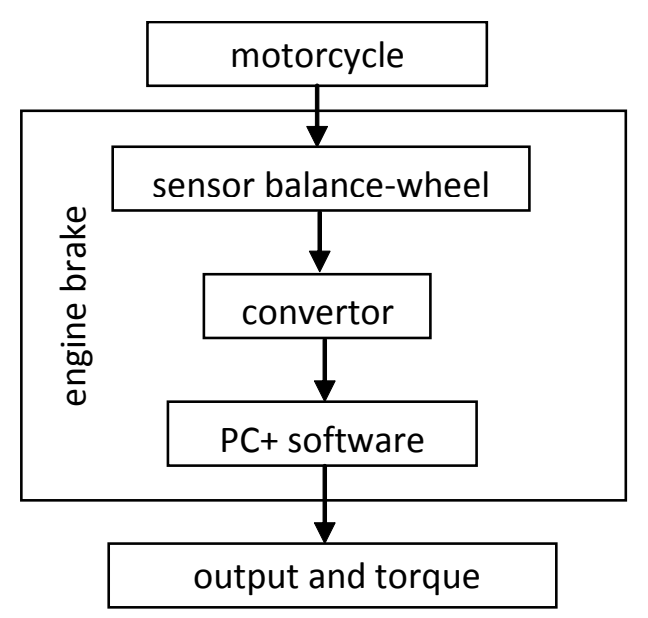

Fig. 4 Block Diagram of Engine Brake

\section{Output Engine Brake}

That is a starting dynamic brake (Fig.3). Its advantage is a possibility to obtain an output-moment characteristic during several seconds. A measurement is performed in place that is why a testing ring is not needed. In Fig. 4 there is the block diagram for data measurement, data operating and data evaluating. The principle consists in an accelerating of constant mass (balance-wheel) which has got a constant moment of inertia. The sensor, which is set on the brake frame, scans every revolution of the balance-wheel and time when the revolution is done. The program determines an average of times from the certain number of revolutions. The time-lag between individual averages is pro- 
portional to an output increment. The operating period of one measurement is relative short (circa several seconds). After what the measurement is finished, the software calculates the functional relation among engine output, torque and engine revolutions (Fig. 6).

\section{Engine Watch and Control System - EWaC}

That is a data-recording system, i.e. a device which scans and stores information during a motorcycle ride (in real conditions, in real loading). This device makes possible to diagnose parameters of a twostroke combustion engine: an output, a torque and their behaviours, a temperature of exhaust system and its behaviour, detonating strokes and their number per time unit and other characteristics. A number and a kind of scanned parameters are related to the types and a number of sensors which are installed on the two-stroke. The block diagram for data measurement, operating and evaluation is similar as output engine brake is but there is a difference of its output. The engine activity record in dependence on time is the result of this system.

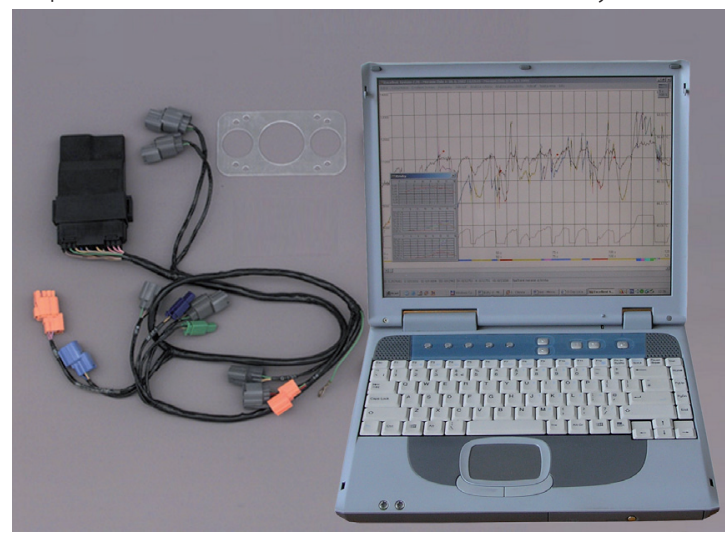

Fig. 5 Engine Watch and Control System

The principle of EWaC system is in the measurement of the engine instantaneous speed, an instantaneous temperature of exhaust system and scanning of active speed gear or further parameters. The system does a functional record of engine activity on the base of scanned and entered data (a wheel circumference, gear ratios of individual speed gears, a curve of air resistance and a motorcycle weight). This record is stored in the memory of EWaC system. After finishing of the measurement, it is possible to copy the record by mean of parallel port into PC (Fig. 5). On PC display (Fig.10) there is the record of engine activity in dependence on a time axis graphically presented (by means of the software which is a component of EWaC system). Every point of the record covers an instantaneous speed, detonating strokes, a temperature of exhaust system and an output at a crank shaft end $[5,6]$.

\section{Experimental Results \\ 2.1 Analysis of Exhaust System Length Influence on Out- put Characteristic}

The performed measurements are intent on the analysis of an exhaust system length influence with an output characteristic in consideration of the defined aim. The motorcycle Aprilia RS 125 was used as an experimental model. Aprilia RS 125 is equipped with the engine ROTAX 122 (Fig. 2).

A standard exhaust system, used in the motorcycle Aprilia RS 125, was applied for the first measurement APR1. The second measurement (APR2) was performed with the same exhaust system which had the 5-mm-trimmed exhaust pipe (Fig.1). For the realisation of APR3 measurement there was the exhaust system again shortened. The system had the 10-mm-trimmed exhaust pipe.

The measurement device was used the output engine brake (Fig. 3). In Fig. 6, 7, 8 there are illustrated graphically the measured dependences of an output and a torque on engine speed with using of various exhaust system variants. An upper curve represents the dependence an output on revolutions; a bottom curve represents the behaviour of torque. In Fig. 9 there is the comparison of these measurements.

The range of exploitable speed, i.e. revolutions in which there is constantly kept the high value of instantaneous output (over 22,4 kW, i.e. $30 \mathrm{HP}$ ) and the torque (over 19,6 Nm, i.e. $2 \mathrm{kpm}$.), is the most important parameter in term of the practical application. In Tab.2 there are the measurement results and the individual ranges of exploitable engine speed displayed.

Axis: $\mathrm{x}$ - axis revolutions per minute, $\mathrm{y}$ - axis (left) output [HP], i.e. $x 0,7457[\mathrm{~kW}], z$ - axis (right) torque $[\mathrm{kpm}]$, i.e. $x 9,81[\mathrm{Nm}]$, This system operates only with HP and kpm.

Upper legend in the graphs: MOTOR - engine, VYFUK exhaust port, KARB. - carburettor, ZAPAL. - ignition, Q.S.K. - capacity of combustion space, STRB. - distance between the piston and head, TLAK - pressure, TEPL - temperature, VLHK. - humidity, BENZ. - 


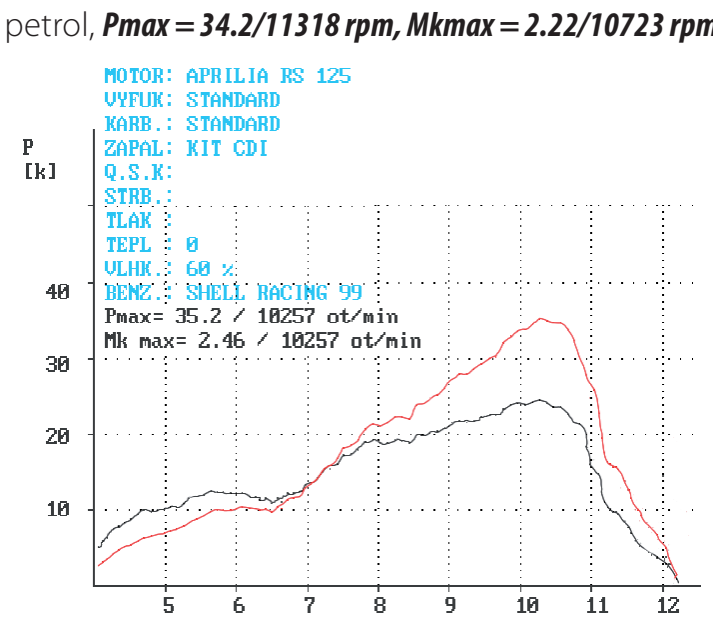

Fig. 6 Output and Torque Behaviour with Using of Standard Exhaust System (APR1)

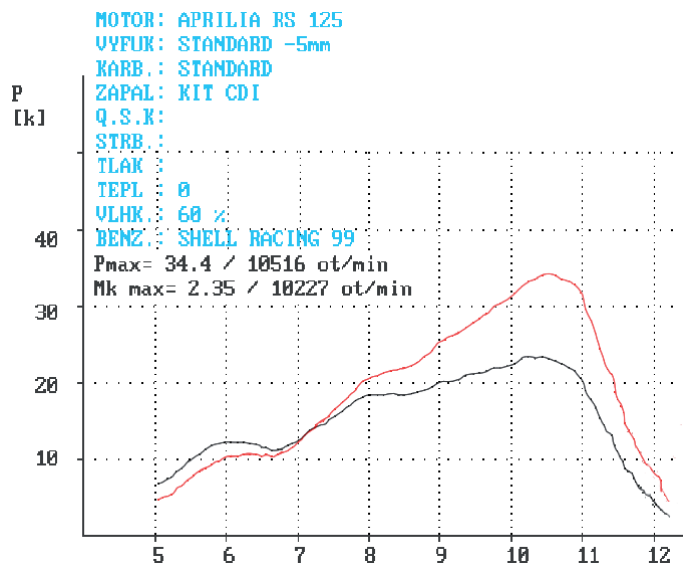

Fig. 7 Output and Torque Behaviour with Using of 5-mmtrimmed Exhaust System (APR2)

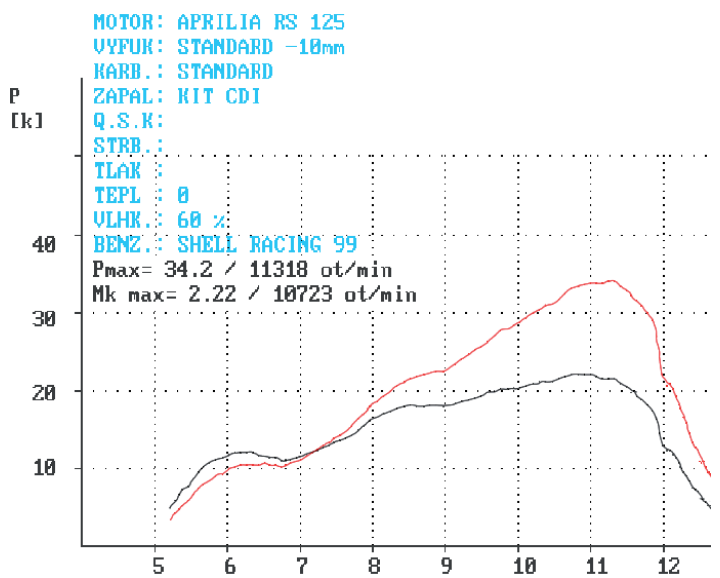

Fig. 7 Output and Torque Behaviour with Using of 5-mmtrimmed Exhaust System (APR2)

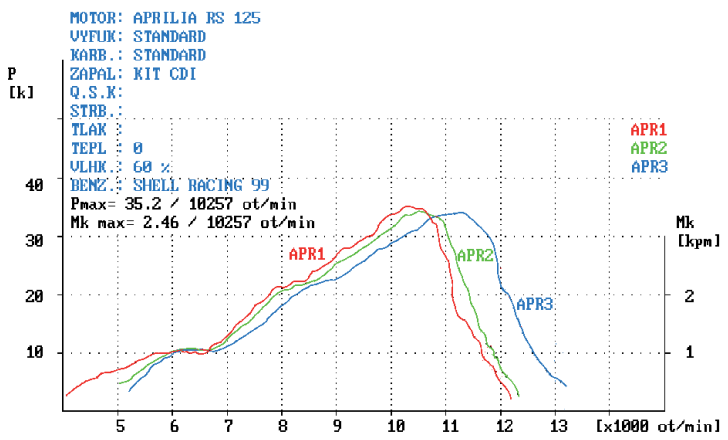

Fig. 9 Comparison of Output Behaviours with Using of All Three Exhaust Systems

\begin{tabular}{|l|c|c|}
\hline $\begin{array}{c}\text { Speed range with } \\
\text { the output over } \\
\mathbf{2 2 , 4} \mathbf{~ k W} \\
\text { (30 HP) } \\
\mathbf{n} \text { [rpm] }\end{array}$ & $\begin{array}{c}\text { Speed range with } \\
\text { the torque over } \\
\mathbf{1 9 , 6} \mathbf{~ N m} \\
\text { (2 kpm) } \\
\text { n [rpm] }\end{array}$ \\
\hline $\begin{array}{l}\text { Standard exhaust } \\
\text { system }\end{array}$ & 1200 & 2000 \\
\hline $\begin{array}{l}\text { 5-mm-trimmed } \\
\text { standard exhaust } \\
\text { system }\end{array}$ & 1250 & 2000 \\
\hline $\begin{array}{l}\text { 10-mm-trimmed } \\
\text { standard exhaust } \\
\text { system }\end{array}$ & 1500 & \\
\hline
\end{tabular}

Tab. 2 Measurement Results

\subsection{Analysis of Combustion Products Temperature Influ- ence in Exhaust System for Output Characteristic}

When the exhaust system length is shortened the maximum output and the maximum torque are moved into higher operating speed of the twostroke combustion engine. That is valid at a constant temperature and a constant pressure .

And similarly the sonic wave rate of spread depends on a pressure and a temperature (1) according to the undulatory theory $[1,2]$.

$C=\sqrt{K \times \frac{R \times T}{M}}$

where: $C$ sonic waves rate of spread; $K$ ratio of specific heats; $R$ gas constant; $T$ temperature; $M$ molar mass

A sonic wave rate of spread increases with an accumulative temperature in the exhaust system (1). A maximum and minimum temperature exists theoretically for every exhaust system, defined shape 
and dimensions. The output and torque behaviours increase the most effectively in this thermal interval because the scavenging of two-stroke engine cylinder is optimized by means of the exhaust system. With regard to above-mentioned assumption, the experimental measurements were performed on the base of this prediction and these measurements were intent on the explanation of combustion products temperature in an exhaust system for an output characteristic of two-stroke combustion engine. The measuring device was the Engine Watch and Control System (EWaC system) (Fig. 5). The motorcycle Honda RS 125R was used as an experimental model.

The aim of measurements was defined for the optimal operating thermal interval to achieve a maximum output for used exhaust system.

\section{Three thermal states were used for the measurement in the exhaust system:}

1. Thermal interval from 440 to $540^{\circ} \mathrm{C}$ (Fig. 10)

2. Thermal interval from 520 to $620^{\circ} \mathrm{C}$ (Fig. 11)

3. Thermal interval from 600 to $720^{\circ} \mathrm{C}$ (Fig. 12)

The temperature values were measured at points where the temperature of exhaust system reaches the maximum, i.e. in the area of exhaust pipe, approximately $150 \mathrm{~mm}$ from the upper edge of exhaust port (Fig.1). In the outputs from EWaC system there are displayed the record of engine activity in dependence on time. That is illustrated by means of an upper curve. The concrete section, delimited with both sides, is selected from this curve. In this section there are performed the output analysis (left smaller window) and the temperature analysis of combustion products in an exhaust system (the curve in the middle of the picture). This system operates only with $\mathrm{HP}$ and $\mathrm{Nm}$.

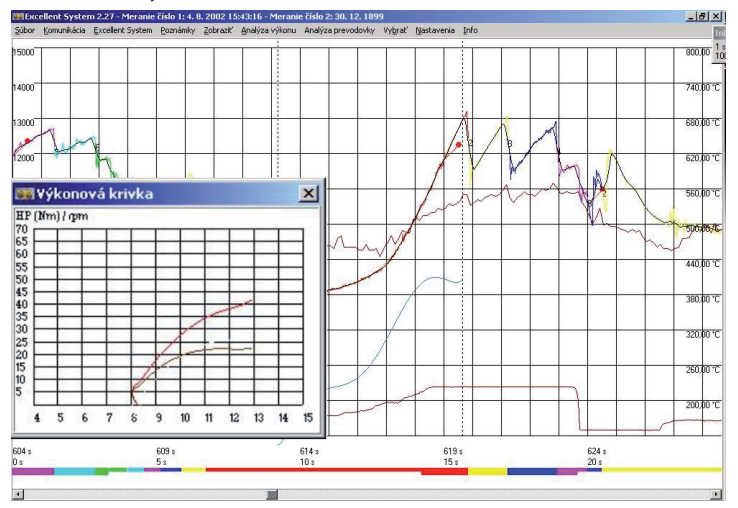

Fig. 10 Activity Record and Output Behaviour of TwoStroke Engine in 1st Thermal State

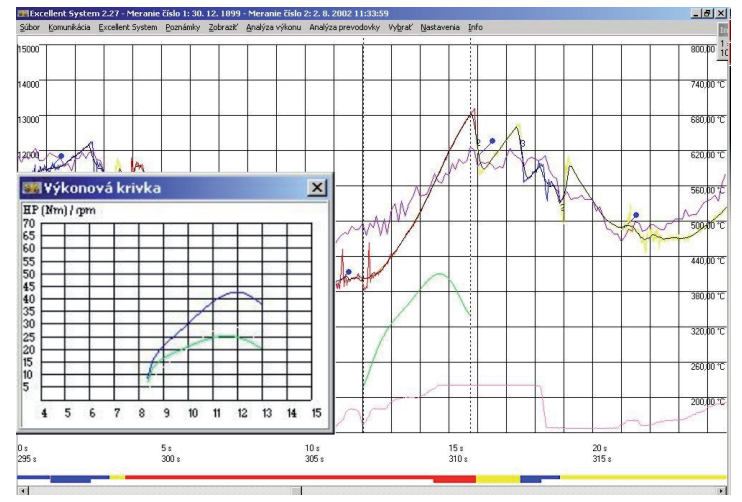

Fig. 11 Activity Record and Output Behaviour of TwoStroke Engine in 2nd Thermal State

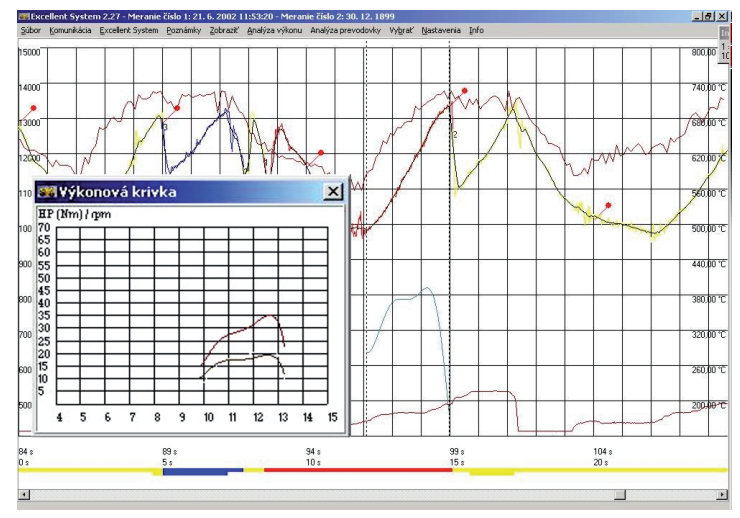

Fig. 12 Activity Record and Output Behaviour of TwoStroke Engine in 3rd Thermal State

An sonic waves rate of spread increases with accumulative temperature (1). In the exhaust system a back wave returns quicker and so the back scavenging process of a cylinder is accelerated. Theoretically, an exhaust system is shortened.

An exhaust system temperature hast to rise with the increasing revolutions of optimal adjusted engine therefore the exhaust system is theoretically shorter at higher speed and theoretically longer (with lower temperature) at lower engine speed. The maximum output and the range of exploitable speed, i.e. revolutions with high value of instantaneous output is constantly kept (over 22,4 kW, i.e. $30 \mathrm{HP}$ ), are important parameters for the practical use.

In Tab. 3 there are the measurement results, the maximum outputs and the ranges of exploitable speed in the individual thermal intervals. 


\begin{tabular}{|c|c|c|}
\hline & $\begin{array}{c}\text { Maximum output } \\
\text { P [kW (HP)]/ } \\
\text { n [rpm] }\end{array}$ & $\begin{array}{l}\text { Range of exploi- } \\
\text { table speed } \\
n \text { [rpm] }\end{array}$ \\
\hline $\begin{array}{l}\text { 1. Thermal inter- } \\
\text { val: from } 440 \text { to } \\
540^{\circ} \mathrm{C}\end{array}$ & $31,3(42) / 13000$ & 2700 \\
\hline $\begin{array}{l}\text { 2. Thermal } \\
\text { interval: from } 520 \\
\text { to } 620^{\circ} \mathrm{C}\end{array}$ & $32,1(43) / 12000$ & 3000 \\
\hline $\begin{array}{l}\text { 3. Thermal } \\
\text { interval: from } 600 \\
\text { to } 720^{\circ} \mathrm{C}\end{array}$ & $26,1(35) / 12500$ & 1100 \\
\hline
\end{tabular}

Tab. 3 Measurement Results

\section{Conclusions}

According to the measurement results analysis in last section the shortening of exhaust system length in the area of exhaust pipe induces the transfer of a maximum output and a maximum torque to the higher operating speed of twostroke combustion engine. Simultaneously the range of operating speed (i.e. revolutions, in which the engine reaches the constant high output, over $22,4 \mathrm{~kW}$, i.e. $30 \mathrm{HP}$ ) is wider. The next contribution is the more fluent increasing of an output and a torque what provides better steering control. This knowledge makes possible the variability of output curve according to the concrete necessity of given single-track vehicle.

According to the measurement results analysis, the $\left.<520 ; 620^{\circ} \mathrm{C}\right\rangle$ is the optimal interval of operating temperatures in an exhaust system for this twostroke combustion engine. The engine reaches the perfect output 32,1 kW (43 HP) at $12000 \mathrm{rpm}$ and the range of exploitable speed is $3000 \mathrm{rpm}$. However, the conditions are not so optimal in this interval of limited values $520^{\circ} \mathrm{C}$ and $620^{\circ} \mathrm{C}$. The highest output is reached if the temperature converges in an exhaust system to the mean value of interval, i.e. $570^{\circ} \mathrm{C}$. The temperature in an exhaust system increased with an output what is characteristic for an optimal adjustment.

In thermal interval $\left\langle 440 ; 540^{\circ} \mathrm{C}\right\rangle$ there was the maximum engine output lower and the range of exploitable speed decreased as well. The exhaust system was overcooled thus theoretically shorter. That is valid predominately for the temperature $440^{\circ} \mathrm{C}$. The exhaust manifold is theoretically shortened toward an upper limit of interval and the en- gine characteristics are improved significantly. In thermal interval $\left\langle 600 ; 720^{\circ} \mathrm{C}\right\rangle$ there was the maximum engine output the lowest and there was the range of exploitable speed practically unavailable. That is valid predominately for the temperature $720^{\circ} \mathrm{C}$. In lower limit of interval $600^{\circ} \mathrm{C}$ there are good output characteristics. The output parameters make significantly worse with the increasing temperature. The system is overheated and theoretically the exhaust manifold is excessively shortened.

In the exhaust manifold the low temperature means that there is an overrich mixture (fuel redundancy) and it follows an imperfect burning.

In the exhaust manifold the high temperature means that there is a weak mixture, it smoulders out in the exhaust manifold, the combustion process takes longer time (fuel lack).

In the exhaust manifold the optimal temperature means that the composition of mixture is optimal and heat is changed into mechanical energy with the high efficiency.

It follows that a temperature in an exhaust system has got a cardinal influence on an engine output characteristic. That is why it is necessary to ensure its optimal interval. It will be important for this thermal interval where the temperature increases proportionately with an operating engine speed and an engine load. It causes theoretically the lengthening (for lower operating engine speed) and theoretically the shortening (for higher operating engine speed) of an exhaust system. This effect provides a higher output in the whole regime of revolutions and decreases a production of emission because there is more perfect combustion here. Now, the highest efficiency of two-stroke combustion engine will be provided.

\section{Acknowledgement}

At the present time the problem of increasing for output parameters of combustion engine is solved in the framework project VEGA 1/0356/11 Innovative processes in construction of driving units applied in transport means, machines and optimisation of material flows and logistics in order to save energy and to increase reliability with regard to application purposes in the practice.

\section{References}

[1] BLAIR, G. P.: Further Developments in Scav- 
enging Analysis for Two-Cycle Engines. SAE 800038,1980

[2] KOŽOUŠEK, J.: Teorie spalovacích motorů, SNTL/ALFA, Praha, 1971 ("Theory of Combustion Engines")

[3] MURÁNSKY, J., BADIDA, M.: Enviromental Compatibility of Mechanical Engineering Products (MEP-s), Acta Mechanica Slovaca, 1/2010, str.72-75, ISSN 1335-2393

[4] PLOHBERGER, D., MIKULIC, L. A.,LAND HRER, K.: Development of a Fuel Injected Tw Gasoline Engine, SAE 880170,1988

[5] SINAY, J., HOEBORN, G., MAJER, I.: Risks in chatronical Systems, Acta Mechanica Slovea, (N) 1/2009, str.58-63, ISSN 1335-2393

[6] ŽIVČÁK, J., KAŤUCH, P., HUDÁK, R.: New Applications of Industrial Computed Tomography in Biomedical Engineering, Acta Mechahica Slovaca, 1/2009, str.50-57, ISSN 1335-2393 *

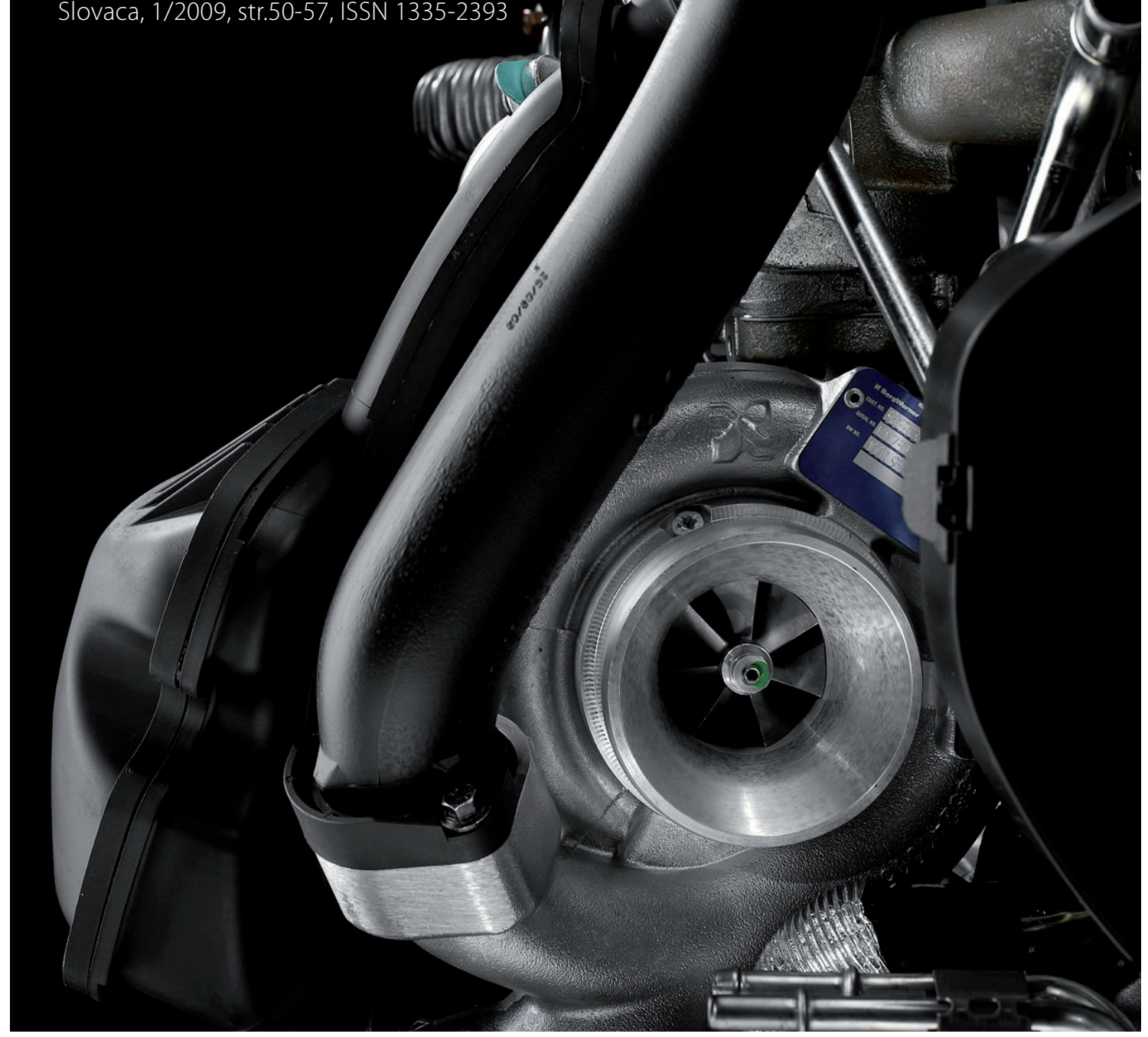

